\title{
Preschool teachers' beliefs about child participation and its implementation in practice
}

\author{
Tatiana Le-van ${ }^{1 *}$ and Anna Iakshina ${ }^{1}$ \\ ${ }^{1}$ Moscow City University, Institute of System Projects, Laboratory of Child Development, Moscow, \\ Russia
}

\begin{abstract}
The implementation of the participatory approach in education allows forming important children's competencies for life in a democratic society. However, in reality, child participation is often reduced. Children, especially young, have the right to make decisions only about their games and personal belongings, but a child's opinion is not credible in the educational process. A more successful implementation of the participatory approach requires resorting to tools that allow objectively considering its strengths and weaknesses in terms of provisions for child participation in decision-making. The study aims to identify the connection between Russian teachers' beliefs about child participation and the quality level of provisions for child participation in the educational process. The methods of survey and structured non-participant observation have been used. The authors have found that, in general, the majority of teachers share the idea of supporting child participation. However, the quality of the learning environment in the context of the examined aspect differs significantly. Sociometric characteristics do not determine these differences. Regardless of the quality level of child participation support, teachers do not seek to expand opportunities for children, and the participatory approach is used only in the preschool classroom. The authors have concluded that despite teachers' stated beliefs about the importance of the participatory approach, its implementation is often falsified. To change the situation, it is necessary to discuss this gap with teachers, clarify true values, and provide them with the necessary means for real child participation.
\end{abstract}

Keywords: preschool teachers, student participation, provisions for participation, true and false participation.

\section{Introduction}

The participatory approach is actively used worldwide in various areas of public life, including education, urban improvement, culture, and politics [1]. The participatory approach in education promotes the development of civil society and democracy [2]. The implementation of the participatory approach allows children to choose and act according to their intentions and express their opinions on various issues. Moreover, it influences the educational process. The key participation criterion is the involvement of children in decision-making in different areas of their lives $[3,4]$. True participation meets the challenges

\footnotetext{
${ }^{*}$ Corresponding author: levantn@mgpu.ru
} 
of modern times, promotes cooperation between people, shows different points of view, and helps to consider different and even opposing needs and interests [4, 5]. Participation is also important for supporting the agency and space of child actualization, where a child creates new products with the support of an adult [6]. It is impossible to learn instantly how to make decisions and express opinions; that is why the preschool classroom creates a context where children's participation rights can be recognized [7,9]. The creation of provisions for child participation is a key competence of a modern preschool teacher and a sign of high-quality practice $[7,8]$. In different countries, national standards and curricula for preschool education emphasize the importance of child agency and the attitude towards children as competent participants in learning [10-12]. At the same time, we observe a shortage of participation practices that expand children's opportunities in decision-making and the substitution of participation by the "game of democracy" $[1,13]$. A national study of the quality of education [14] using the ECERS-R showed that in Russian preschool classrooms, children had very little time for free play and the teacher-centered pedagogy prevailed.

For participation, the adult must consider the child's point of view $[11,15]$. Therefore, teachers need the competence of maintaining a dialogue with children, interpreting their intentions, and teaching them the means of expressing their opinions [16]. Difficulties in supporting child participation can be associated with a different understanding of this concept by teachers [11]. Adults' attitude towards children's preferences and participation is often ambivalent. On the one hand, they recognize their value. On the other, "natural" (without using cultural tools) and literal understanding of preschoolers' ideas provokes the falsification of participation, selection of the most suitable ideas from the point of view of an adult, and creation of a pseudo-child environment that neither supports child initiative nor meets children's needs $[1,17]$. Besides, teachers who facilitate participation find it difficult to determine the boundaries and results of child participation; they do not know how to involve children into decision-making and interpret their statements [4, 13].

The challenges facing modern teachers include supporting children's intentions, making them essential, and allowing children to "participate in building the culture of the future" [6].

The study aims to identify the connection between Russian teachers' beliefs about child participation and the quality level of provisions for child participation in the educational process.

The key questions are:

1. How do teachers' beliefs about child participation and real practice correlate?

2. Do teachers focus on participation when creating learning environment?

\section{Methods}

We conducted our study concerning teachers' understanding of the concept of "participation" using the "Danish Questionnaire" methodology [18]. To avoid socially desirable answers, we discussed its aims before the survey, participation was voluntary, and confidentiality was protected. The survey included information about the age and pedagogical experience of the respondents and the age of children they worked with.

Our study of provisions for child participation implemented in the reality relied on the developed methodology. Its principles correspond to the international practice of quality assessment of the learning environment, for example, ECERS-3 [19]. The methodology is based on Vygotsky's approach and the effective participatory practice parameters identified by McKenna et al. [1]. The methodology assesses how a teacher supports child participation, shows the value of all ideas, offers various cultural tools for expressing children's opinions, and helps to embody children's ideas, considering the needs of children and their zone of proximal development. 
A complex of environmental parameters and features of interaction between a teacher and children was assessed at different levels of quality. A specially trained external expert conducted a 3-hour structured non-participant observation.

The approbation of the methodology based on the methods of contrasting groups and consistency of expert assessments showed a sufficient level of validity (differences in the means were significant at the level of $0.01, \mathrm{P}$-value $=0.002168$ ) and reliability (the share of differences between experts was in $80 \%$ cases no more than 1 point, the average deviation modulus $\mathrm{Me}=0.8$, which is significantly lower than $\mathrm{sd}=1.375$ ).

The study involved 40 teachers from 27 preschool classes.

The respondents were divided into two clusters according to the results of the assessment: the teachers from the low quality classes (from 1 to 3 points, where the maximum is $7, n=31$ ) and the teachers from the high quality classes (from 4 to 6 points, $n=9$ ). We analyzed the responses of the respondents from different clusters in terms of the significance of differences (Student's t-test in Welch-modification with no assumptions about equality of variances, but with the assumption of normal distribution). We also carried out a one-factor analysis (ANOVA) to identify the influence of the age of teachers and their students on the assessment of the provisions for child participation, as well as correlation analysis to identify the connection between the provisions and the working experience of the teacher.

\section{Results}

The low quality cluster showed an average value of the provisions assessment equal to 2.42 $(\mathrm{sd}=0.67, \mathrm{md}=3$; confidence interval: $2.09-2.75$ at $\alpha=0.01)$ and the high quality cluster -4.67 $(\mathrm{sd}=0.87, \mathrm{md}=4$, confidence interval: $3.70-5.64)$. The clusters differed significantly at the indicated level of significance (P-value=1.84E-05).

The qualitative analysis of the provisions typical of the low quality cluster revealed that traces of child participation were present in the overwhelming majority of sample classes. There was no directive manner in teachers' communication. Educators didn't stop children who expressed their own opinion. Children had the opportunity to choose at least their free play, and the authorship of some children's works or ideas was indicated. Yet, situations of choice and opinion expression in teacher-led activities and the feedback on how their opinions influenced decision-making were not typical.

In the high quality classes, teachers regularly created child-initiated and teacher-initiated activities, where children could express their opinions using appropriate cultural tools (for example, voting, a choice board, or something else). The value of a child's solution or intention and different points of view were respected. However, the expansion of children's influence beyond the boundaries of class life, for example, decorating the common rooms of the building or participation in social projects of the district, was not typical even of the high quality classes.

Analysis of variance showed that the ages of teachers and children were not significant factors for the provisions for child participation (for teachers' age, P-value $=0.465$, the share of explained variation was $4 \%$; for children's age, $\mathrm{P}$-value $=0.876$, the share of explained variation was $1 \%$ ). The check on the normality of distributions and homogeneity of variances (Bartlett's test) for both factors demonstrated the correctness of the ANOVA with the P-value of the error of rejecting the null hypothesis at a level of more than 0.05 in both cases.

Even though it was not possible to statistically prove the decisive influence of these factors due to small sample sizes, there was a tendency for the average values of the assessment of provisions supporting child participation to decrease as the age of the teachers increased. For classes where the teachers were 20-35 years old, it was 3.25, 36-50 years old - 2.93, and 51-60 years old -2.40 . We did not observe such dependence concerning children's age groups even at the level of a trend. In classes where children were $0-3$ years 
old, the average value of the assessment of the provision was $2.50,3-5$ years old -2.96 , and 6-7 years old -2.92 .

The correlation analysis of the teachers' working experience and the provisions for child participation did not give significant connections ( $\rho=-0.27$ is insignificant).

There were very few significant differences (at the $\alpha=0.01$ level) in the answers of the teachers representing the selected clusters. In the answer to the question "Situations for learning", only one option helped to find such differences. It was "Situations which contribute to children's social development". This choice was significantly more often made by the teachers of the high quality cluster. In the answer to the question "Optimal conditions for learning", the significant differences appeared only in the option "Preschool teachers are in active interaction with children and support them".

We found two more choices that did not show significant differences at the 0.01 level but became significant at the 0.05 level: "Free play" in the first question and "Participating in activities on children's interest with adults" in the "How children learn" question.

None of the eight answers to the question "Participation is..." suggested to the respondents showed significant differences between the clusters. The respondents more often assigned them the 1 and 2 priority ranks (the share of respondents who made such choices was from 74.2 to $100 \%$ ).

\section{Discussion}

The study showed that both Russian and foreign teachers recognize the value of child participation. However, while generally understanding it similarly, Russian teachers implement polar opposite strategies in comparison with their foreign colleagues [10]. Thus, the similarity of answers may indicate a blurred understanding of this concept (all options were assessed as equal), which in reality narrows the possibilities for child participation [12]. In the high quality classes, children's opinions were more valuable and teachers support provisions for them to discuss important aspects of life and make decisions together. In the low quality classes, teachers were interested in children's opinions rather formally and did not give children any feedback on them. Children could make decisions only about their play and personal belongings, which is a serious gap in the implementation of child participation [4] and can provoke participation falsification [1]. The general tendency is that, regardless of the quality level, the emergence of child participation is noticeable only within the preschool classroom: children's influence on decision-making, even on issues accessible to them, does not extend beyond it.

Despite the assumption that the sociometric characteristics of the respondents may be the determinators of the differences in the quality level of provisions for child participation, this has not been statistically confirmed and requires further testing on a larger sample.

\section{Conclusion}

Despite teachers' stated beliefs about the importance of the participatory approach, in reality, it was either not implemented or falsified. In the low quality classes, teachers saw their mission in a direct demonstration of cultural examples, which contradicts actual ideas about teaching that develops children's initiative and agency [6].

To change the situation, it is necessary to discuss this gap with teachers, clarify true values, and provide them with necessary means for real child participation. Precise wording in diagnostic tools, examples and observable signs supply, and development of a methodology for studying teachers' beliefs that minimizes the risk of getting socially desirable answers can help. 


\section{References}

1. L. Day et al., Evaluation of legislation, policy and practice of child participation in the European Union (EU). Final Report (Publications office of the European Union, Luxemburg, 2015). https://doi.org/10.2838/45596

2. J. Dewey, Democracy and education: An introduction to the philosophy of education. (Columbia Univercity, New York, 1915). Accessed on: December 16, 2020. [Online]. Available: https://s3.amazonaws.com/arenaattachments/190319/2a5836b93124f200790476e08ecc4232.pdf

3. J. Flutter, The Curriculum Journal, 18(3), 343-354 (2007). https://doi.org/10.1080/09585170701589983

4. S. Sheridan, I. P. Samuelsson, Contemporary Issues in Early Childhood, 2(2) (2001) https://doi.org/10.2304/ciec.2001.2.2.4

5. I. P. Samuelsson, E. Park, International Journal of Electronic Commerce, 49(3), $273-$ 285 (2017). https://doi.org/10.1007/s13158-017-0197-1

6. N.E. Veraksa, Cultural-Historical Psychology, 14(2), 102-108 (2018). https://doi.org/10.17759/chp.2018140211

7. M.A. Theobald, A. Kultti, Contemporary Issues in Early Childhood, 13(3) (2012) https://doi.org/10.2304/ciec.2012.13.3.210

8. I. Siraj-Blatchford, K. Sylva, British Educational Research Journal, 30(5), 713-730 (2004). https://doi.org/10.1080/0141192042000234665

9. J. Kangas, Enhancing children's participation in early childhood education through the participatory pedagogy. Thesis (Unigrafia, Helsinki, 2016)

10. Ministry of Education of the Russian Federation, Federalnyi gosudarstvennyi obrazovatelnyi standart doshkolnogo obrazovaniya [Federal State Educational Standard of Preschool Education]. Rossiyskaya gazeta, 265(6241) (2013)

11. I. Johansson, A. Sandberg, European Early Childhood Education Research Journal, 18(2), 229-242 (2010). https://doi.org/10.1080/13502931003784560

12. Ministry of Education, Te Whariki. Early childhood curriculum (Learning Media, Wellington, 2017)

13. J. Kangas, T. Venninen, M. Ojala, Australasian Journal of Early Childhood, 41(2), 8594 (2016). https://doi.org/10.1177/183693911604100212

14. I.B. Shiyan, S. Zadadaev, T. Le-van, O. Shiyan, Findings of the national study for the preschool education quality in Russia, in ECCE 2018 VII International Conference Early Childhood Care and Education. The European Proceedings of Social \& Behavioural Sciences, July 2018, Moscow, Russia (2018). https://dx.doi.org/10.15405/epsbs.2018.07.80

15. E.S. Manassakis, Journal of Early Childhood Research, 18(1), 18-28 (2020). https://doi.org/10.1177/1476718X19882714

16. A. Church, A. Bateman, International Journal of Early Childhood, 51, 265-281 (2019). https://doi.org/10.1007/s13158-019-00250-7

17. T.N. Le-van, B.A. Filatova, L.V Gurary, A.N. Iakshina, A.A. Rodionova, Participatory design of schoolyards with children and the whole school community, in Collection of articles after the Second Annual International Symposium. Education and City: partnership for success, 16-18 May 2019, Moscow, Russia (2020) 
18. S. Brostrom, I. Johansson, A. Sandberg, T. Frøkjær, European Early Childhood Education Research Journal, 22(5), 590-603 (2012). https://doi.org/10.1080/1350293X.2012.746199

19. T. Harms, R.M. Clifford, D. Cryer, Early Childhood Environment Rating Scale (ECERS-3) (Teachers' College Press, New York, 2014) 